\title{
Simultaneous multidisciplinary care pathway for back pain: a new approach for a first-level comprehensive evaluation and treatment to guarantee adequate pain relief and recovery
}

\author{
Massimo Allegri ${ }^{1-5}$, Massimiliano Sacchelli2-5, Dino Sgavicchiaa, ${ }^{4,5}$, Vincenzo Manna ${ }^{4,5}$, Fabio Cappabianca ${ }^{4,5}$, \\ Gabriele Mezzetti ${ }^{4,5}$, Tommaso Laddomada ${ }^{1}$, Roberto Citarella ${ }^{2}$, Michele Incerti ${ }^{2,4-6}$ \\ ${ }^{1}$ Pain Therapy Service, Policlinico Monza Hospital, Monza - Italy \\ ${ }^{2}$ Centro Terapia Riabilitativa Private Clinic, Reggio nell'Emilia - Italy \\ ${ }^{3}$ Italian Pain Group, Milan - Italy \\ ${ }^{4}$ Piccole Figlie Hospital, Parma - Italy \\ ${ }^{5}$ M3Salus, Parma - Italy \\ ${ }^{6}$ Neurosurgery Department, Policlinico Monza Hospital, Monza - Italy
}

\begin{abstract}
Low back pain continues to be a major clinical challenge with high direct and indirect societal costs. It is a complex disease with complex pathophysiology both for acute and chronic low back pain.

Although there is consistent evidence about multidisciplinary treatment of low back pain, several different approaches and techniques are proposed, with different results often conflicting among them. In fact, even though the multidisciplinary approach is widely accepted, it is generally applied in different steps involving only one health care providing for each approach. This approach not only does not guarantee a real multidisciplinary vision of this disease but also lacks evaluation of the dynamic changes of the disease according to real patients' needs. In our hospital setting we have developed a "simultaneous multidisciplinary care" of low back pain patients in order to overcome these problems and to satisfy all patients' needs by evaluating and treating all problems causing and related to low back pain. Starting from the existing literature we propose our approach as a new pathway to treat low back patients with a simultaneous multidisciplinary approach.
\end{abstract}

Keywords: Back pain, Chronic pain, Multidisciplinary approach, Radiofrequency, Rehabilitation, Spinal fusion

\section{Introduction}

Low back pain (LBP) is an increasingly prevalent disability/ disorder irrespective of diagnostic and therapeutic improvements (1). Complex environmental, genetic, and clinical factors come together to form the basis for LBP pathophysiology. Furthermore, analgesics and surgery are even more frequently not effective, with unimodal treatment approaches in terms of providing analgesia (2) with increasing rates of low

Received: December 29, 2020

Accepted: April 8, 2021

Published online: July 1, 2021

Corresponding author

Massimo Allegri

Pain Therapy Service

Italian Pain Group

Via Carlo Amati 111, Monza - Italy

allegri@italianpaingroup.com back surgery not necessarily translating to decreased rates of disability (3). Hence, a new, stratified multidisciplinary approach is needed in patients with LBP to provide more targeted, effective, and appropriate treatments. The need for new integrated approaches is further supported by direct and indirect costs associated with LBP. In 2014 it was estimated that the costs in the United States for prescribed drugs for nonmalignant chronic pain was $\$ 17.8$ billion/year (4). Furthermore, in 2010 considering also indirect costs such as chronic pain, the societal economic impact is larger than those created by cardiovascular, cancer, and diabetes combined (5). More recently, in 2019 it was estimated that the overall societal costs of chronic pain in Austria were more than $€ 10,000$ per year per patient (6). Considering these costs it is easy to understand LBP cost, as among all chronic pain condition, it is the most frequent cause of nonmalignant chronic pain (7).

One of the most important elements of assessing and treating LBP is the identification of individuals with acute pain who are at higher risk of developing chronicity through patient-specific psychosocial characteristics (yellow and red 
flags) (8) and through a careful delineation of pain generators, as personalized medicine requires. In the future, it will progressively be more critical and routine to consider genomic biomarkers (9) that will be helpful not only for predicting patients at greater risk of developing chronic pain subsequent to acute episode, but also for leading physicians to a better understanding of patients' pain pathophysiology and helping them to choose the optimal treatment (10). As LBP is a dynamic process with several environmental factors that can interplay in modifying this disease, genomics will hopefully become more effective than genetics in guiding physicians in phenotyping patients and choosing the appropriate treatments (11).

Unfortunately, as genomics biomarkers other than those through pharmacogenomics $(12,13)$ are not still available for clinical practice, it is important to more clearly define multidisciplinary care pathways to better treat LBP patients. Recently, Gatzinsky et al (14) have proposed a pathway for patients who continue to complain of back pain even following back surgery (Failed Back Surgery Syndrome-FBSS). After determining whether resurgery is necessary, they proposed four other levels of interventions: rehabilitation, neurolytic blocks/lesions, spinal cord stimulation, and, finally, other noninvasive options. The value of this approach is its provision of specific pathways for patients. However, the weakness of their proposed approach is that its effectiveness could be compromised by the failure to perform its different levels simultaneously, adapting the level of intervention to the dynamic changes frequently evidenced in LBP patients.

In order to better treat LBP, we propose a model that both creates distinct pathways for acute and chronic pain conditions and the clinical differentiation between patients at low vs. high risk for developing chronic pain. As a risk stratification measure, the STarT Back Tool is a reliable questionnaire for identifying risk for poor outcome in both acute (15) and chronic LBP (16). Hence, it can be a viable questionnaire for defining levels of interventions (17).

Once the level of risk is defined, current guidelines identify several rehabilitation approaches, neurosurgical interventions, pharmacotherapies, or injections/lesion. These alternatives may be effective as unimodal treatment or may be considered as aspects of an algorithm involving multiple interventions in various sequences.

Rehabilitation is widely considered the cornerstone of treatment of acute and chronic $\operatorname{LBP}(18,19)$. Guidelines agree that rehabilitative treatments should be adapted to the specific patients, yet a lack of standardization results in the absence of a strong evidence of a specific treatment, with the exception of graded exercise and cognitive behavioral intervention (20). Several different rehabilitation models are proposed $(21,22)$, but they are seldom related to pain pathophysiology or pain originator (10).

If rehabilitation fails and/or neurological deficits are evident, neurosurgery can be considered as solution of the problem in order to restore function and guarantee an adequate pain relief (22). Nevertheless, in the last years National Institute for Health and Care Excellence (NICE) guidelines have suggested to not consider spinal fusion as a routine treatment for treatment of nonspecific LBP (23). Also for neurosurgical solutions, the problem mainly relies on good selection of patients and to the need of simultaneous care associated with pain treatment and adequate rehabilitation approach.

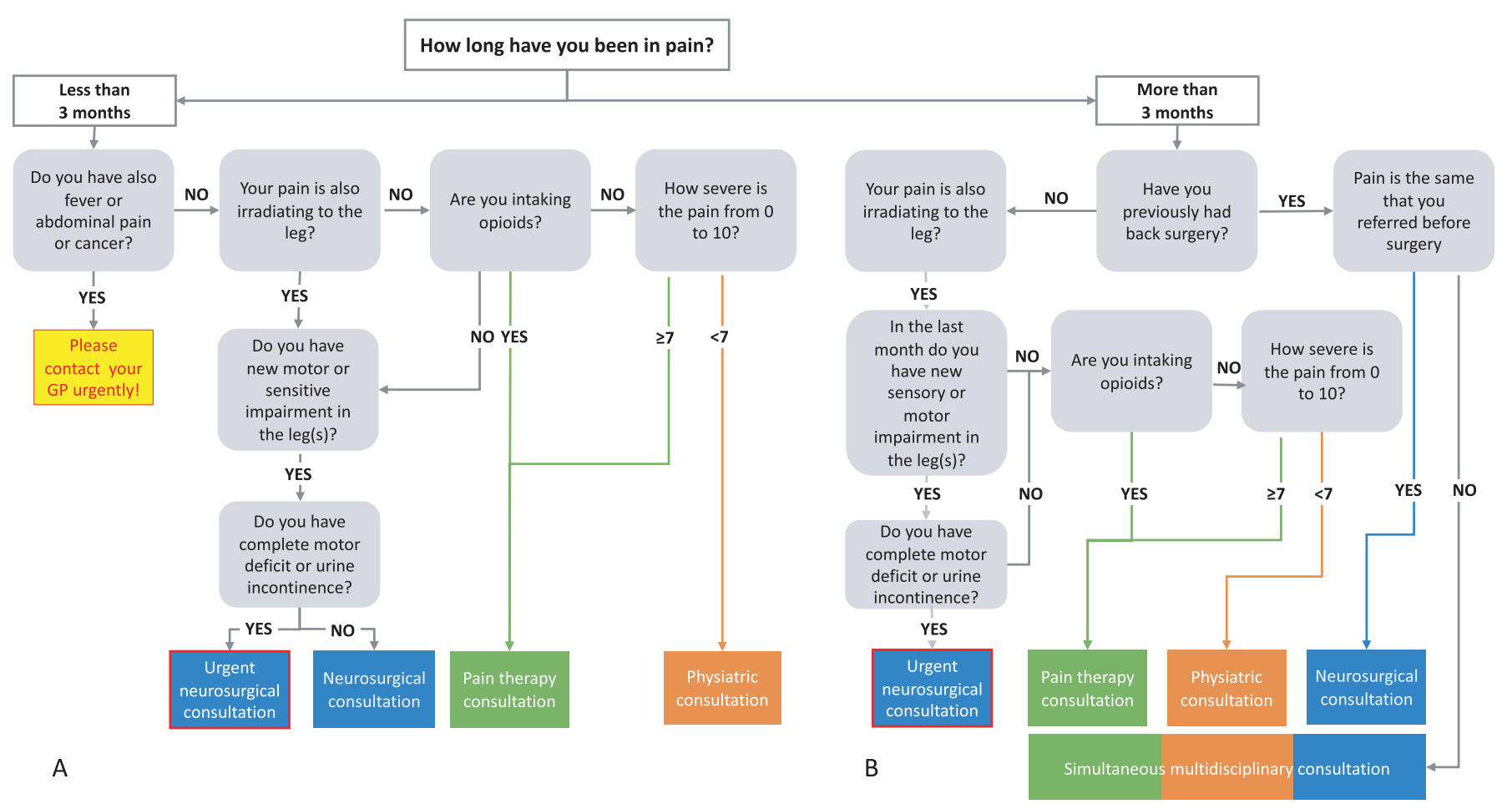

Fig. 1 - Flow chart to define which physician has to evaluate at first consultation patient with acute (A) or chronic (B) low back pain. 
The cornerstone in the treatment of LBP patients is to actively involve patients in the definition of selected outcomes adapting intervention to what exactly physicians and patients are looking for (24).

Evaluation of pain intensity and type of drugs taken is another method to stratify patients. Recently (25), a higher value of pain and the use of higher dose of opioid were associated with higher risk of recurrence of back pain in the year after an acute episode. These data underline not only the importance of definition of the risk to choose the interventions but also the need for a simultaneous evaluation from different health care providers in order to adapt multiple interventions to the dynamic process of the disorder LBP.

In fact, considering all different interventions alone, without a multidisciplinary approach, rehabilitation programs can produce the same effect as radiofrequency (26), that is, the opposite of what is widely accepted by current evidence $(27,28)$. Independently of the several bias and of the not accurate selection of the patients (29), Juch et al (26) show that in order to treat the disorder "LBP" we cannot simply compare a single procedure with another one, but there is a specific need for a simultaneous pathway care in which physicians, physiotherapists, and psychologists can act together according to specific needs of the patients in a specific moment.

In fact, patients' perspectives and needs (30) should always guide multidisciplinary approach, and there are still few patient-centric approaches where all health care providers simultaneously act.

In this article, we present our simultaneous patient-centered multidisciplinary care for LBP that we are currently using in our centers established in the last two years.

\section{Simultaneous patient-centered multidisciplinary care pathway}

In three hospitals (Policlinico Monza Hospital, Centro Terapia Riabilitativa Reggio Emilia, and Piccole Figlie Hospital Parma) we have created a simultaneous patient-centered multidisciplinary care program for all acute and chronic LBP patients.

A physician (a neurosurgeon or a physiatrist or a pain therapist) will evaluate LBP patients and define a specific program for each patient to provide a resolution of the pain through two paradigms: continuous rehabilitation program and simultaneous evaluation of different physicians who can evaluate the dynamic process of LBP exactly when they are necessary.

Hence, the program is centered on two pillars: simultaneous evaluation of specific patients and simultaneous evaluation by all the health care providers needed.

All interventions/consultations are always followed by a phase of rehabilitation in groups to guarantee a better return to previous functional status and solving also the eventual postural problems that have caused LBP.

The program is divided into three phases:

1. definition, according to the patients' needs, of the first physician who has to take care of the patient in his/her

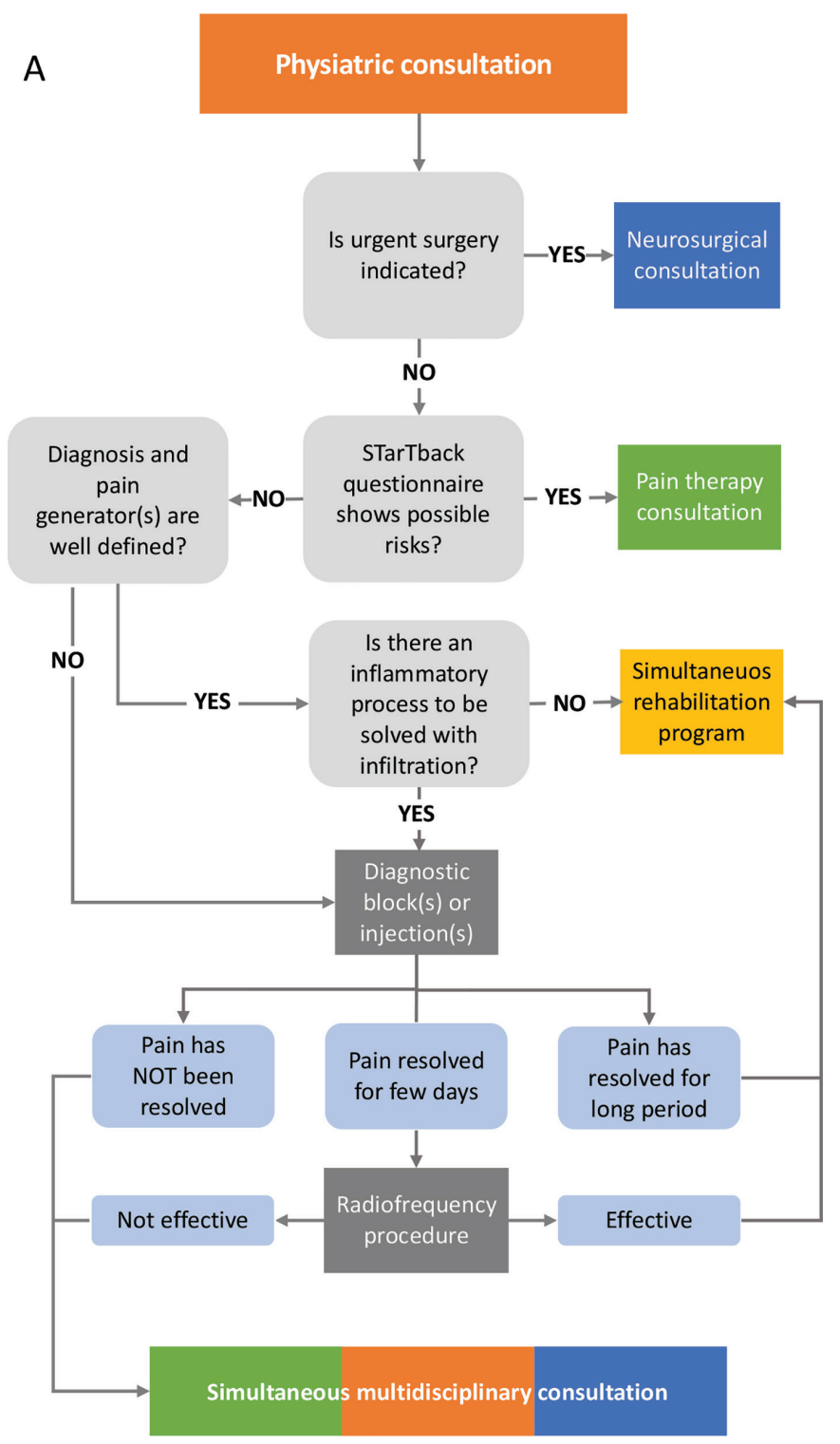

Fig. 2 - Flow chart of the first evaluation by physiatrist (A), pain therapist (B), and neurosurgeon (C).

first consultation (Fig. 1A, B) accordingly to patients' needs

2. simultaneous multidisciplinary care to solve the acute or chronic low back problem (Fig. 2)

3. simultaneous rehabilitation program specifically designed for patients always under a continuous evaluation of physiatrist and pain therapist (if there is pain during the rehabilitation)

\section{Phase 1: first evaluation}

Once a patient is admitted to the clinic for LBP (Fig. 1A, B), through a screening with few questions, we suggest the best physician with whom to have the first consultation: physiatrist, pain therapist, or neurosurgeon. 


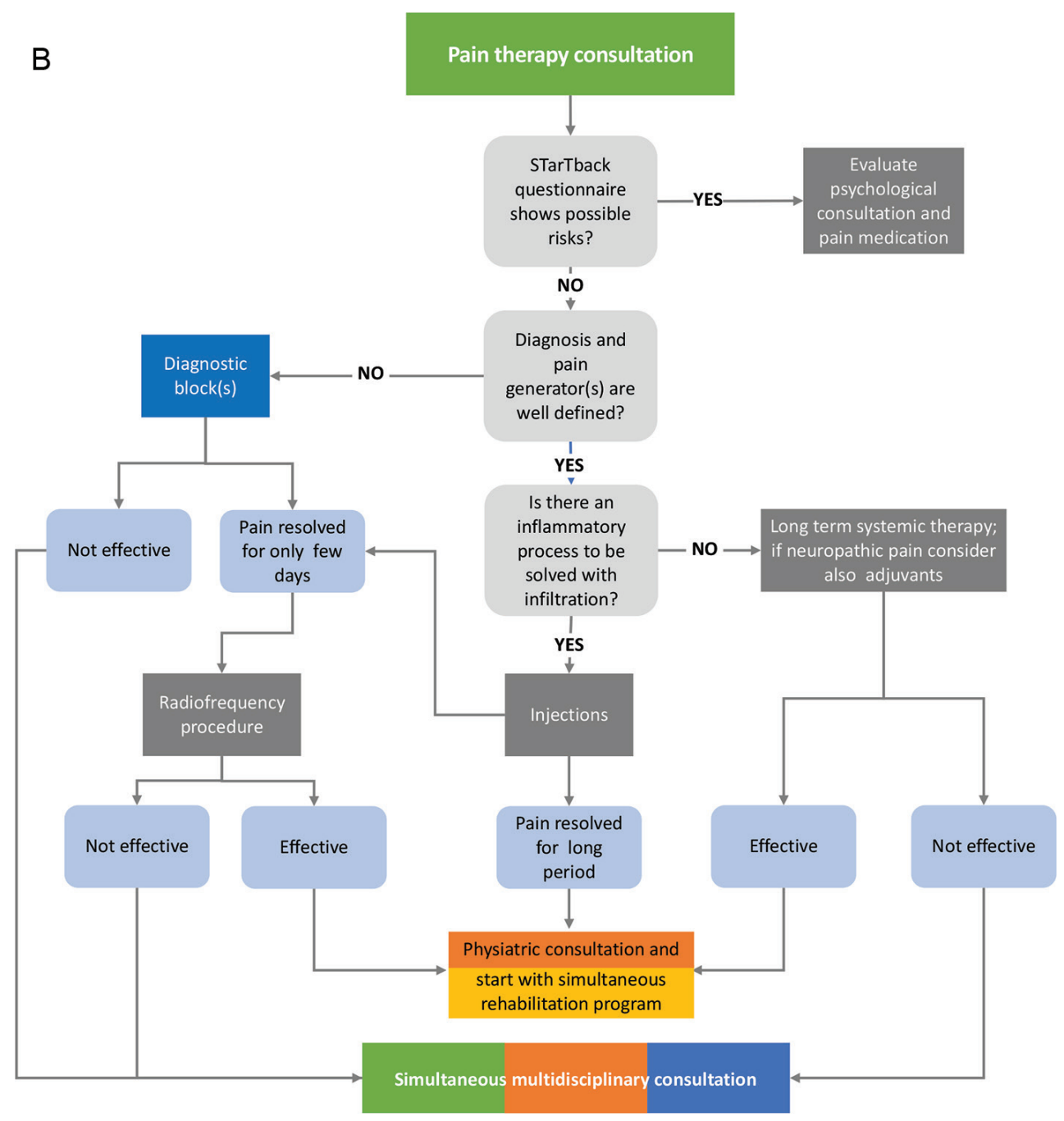

Fig. 2 (Continued) - Flow chart of the first evaluation by physiatrist (A), pain therapist (B), and neurosurgeon (C).

The objective of the first evaluation is:

1. to evaluate severe clinical signs that require urgent medical or surgical hospital admission;

2. to define, as much accurately as possible, the pain generator and pain pathophysiology (7), defining also all postural and mechanical problems to be addressed in the rehabilitation program;

3. to obtain an adequate pain relief for rehabilitation without pain, improving the self-healing potential of the patients.

Hence the best approach possible to treat LBP is defined as regaining the functional status before LBP onset. Once the clinical problems that require urgent hospital admission or surgery are excluded, the patient started with simultaneous multidisciplinary program always centered on their needs and expectations.

\section{Phase 2: simultaneous multidisciplinary care}

The physiatrist (Fig. 2A) evaluates the pain generator and pain pathophysiology in order to establish the more appropriate simultaneous rehabilitation program (phase 3). If patients have a high score on STarT Back questionnaire (11), the rehabilitation will start after pain therapist, and, eventually, a psychologist evaluation, in order to set up an adequate "protective" analgesia.

Patient is also referred to the pain therapist in these two other cases:

1. need to better define, through a diagnostic block (also with selective block of the muscle considered the cause of pain), the pain generator

2. pain hinders an adequate rehabilitation. In this case the appropriate block(s) (epidural injection, facet or sacroiliac joint block) will be performed or (if the pain relief was adequate but for a limited period of time) radiofrequency procedure will also be planned. This approach will have the objective to perform rehabilitation without pain.

After pain procedures, patient will start with the simultaneous rehabilitation defined by physiatrist with a reevaluation after having done half of the rehabilitation program (or also during rehabilitation if pain or patients' new needs come out). 


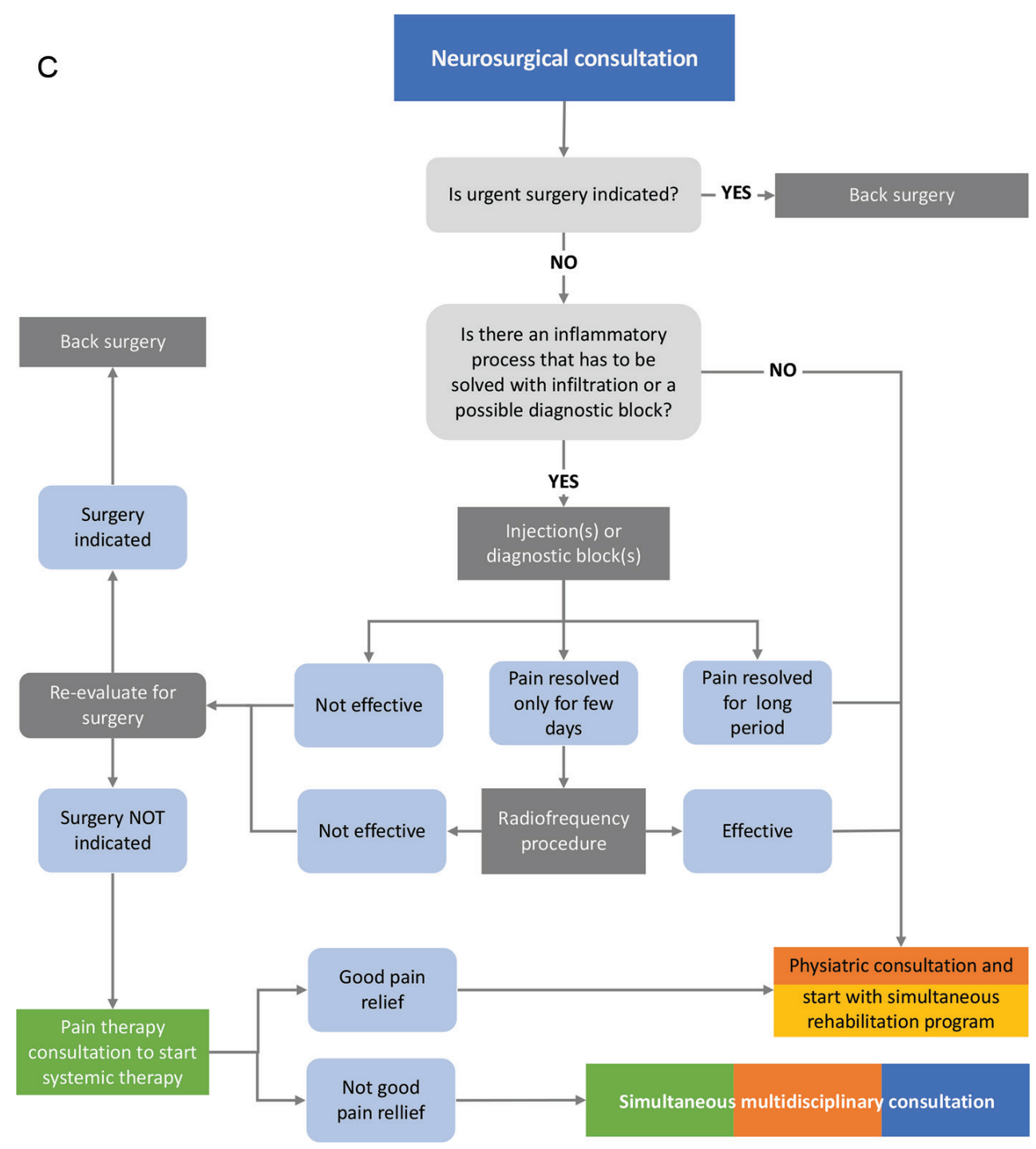

Fig. 2 (Continued) - Flow chart of the first evaluation by physiatrist (A), pain therapist (B), and neurosurgeon (C).

If after diagnostic block(s) or injection(s) has not resolved the pain and/or a clear pain generator has not been found, a simultaneous multidisciplinary consultation is then planned with a psychologist.

The pain therapist (Fig. 2B) will look at pain generator and/ or if there is a neuropathic component. If patients have a high score in STarT Back questionnaire, a psychological evaluation will be done if necessary. Once the pain generator is defined, if there is no surgical indication, an infiltration (epidural, facet or sacroiliac joint block, ultrasound-guided diagnostic block) will be performed to confirm the diagnosis to resolve the inflammatory pain. If pain has a greater inflammatory component and we cannot control it with steroids, regenerative medicine will also be considered. If at least $50 \%$ pain relief for a few days can be obtained, a radiofrequency lesion will be performed. After the block and/or mini-interventional technique, the patient will be immediately referred to simultaneous rehabilitation program chosen accurately according to the type of block or lesion performed and always supervised (see phase 3 ) by a physiatrist. If pain cannot be treated with a specific block, a systemic pain treatment will be planned in order to make rehabilitation less painful as possible.

If after diagnostic block(s) or injection(s) pain has not been resolved and/or a clear pain generator has not been found, a simultaneous multidisciplinary consultation is planned with a psychologist.

The neurosurgeon (Fig. 2C) evaluates first if there is any urgent indication to surgery. If not, the patient is referred to the physiatrist for simultaneous rehabilitation program (phase 3 ). If there is a deferrable surgical indication, the patient is referred to a pain therapist for the most appropriate block(s) (epidural injection, facet or sacroiliac joint block). If conservative treatment is not effective, the neurosurgeon reevaluates the patient for possible surgical procedure or refers him to a rehabilitation program. If the diagnostic block is effective only for a few days, a radiofrequency procedure is planned. After that, the patient will be reevaluated by a neurosurgeon to define if there is still indication for surgery or if patient can be referred to simultaneous rehabilitation program with a psychologist. 
If there is no clear surgical indication and, after diagnostic block(s) or injection(s), pain has not been resolved, a simultaneous multidisciplinary consultation is planned.

Finally, all patients who have not been referred to pain relief from a first approach and patients with complex pain are evaluated in a specific simultaneous multidisciplinary consultation in which physiatrist, neurosurgeon, pain therapist, and psychologist evaluate other diagnostic approaches or other type of second-level surgical procedures, such as new back surgery, spinal cord stimulation, or spinal pumps.

\section{Phase 3: simultaneous rehabilitation program}

After the first evaluation and identification of pain generator, a specific rehabilitation program is defined. If postural problems are identified, an analysis of the movement, through a high-definition dynamic motion capture, is performed before starting injections or radiofrequency procedures and after the rehabilitation program in order to make the postural effect of our treatment more objective as possible.

Rehabilitation is performed through manual therapy and physical therapy, followed by a program in the swimming pool, always according to patients' pathophysiology and type or surgical procedures performed. All the process is performed under the supervision of a physiatrist. Halfway through the program, there is a reevaluation by the physiatrist in order to adapt the program to possible new needs of the patients. If patient mentions moderate pain, a new pain therapist consultation is planned in order to reduce pain as much as possible and to improve the speed of recovery.

At the end of program, there will be a final consultation with the first physician who evaluated the patient. If needed, a rehabilitation program in groups of 5 people will be conducted twice a year to maintain low back wellness.

\section{Limitation of the study}

The main limitation of this program is that we have not yet validated it in properly designed trials. Currently, we have a preliminary evaluation of patients who have been treated in Policlinico of Monza, where we have demonstrated that $70 \%$ of patients who had a first neurosurgical consultation for surgery were effectively treated by simultaneous pain therapy and rehabilitation approach without need of surgery.

Next step will be a validation of the model considering its cost-effectiveness from the point of view of both clinical effectiveness and reduction of societal and patient expenditure avoiding unnecessary consultations or interventions.

\section{Conclusion}

Our simultaneous multidisciplinary care program has the objective to obtain both a good pain relief and adequate improvement of the patient's pain, guaranteeing, in a single simultaneous program, all personalized treatments

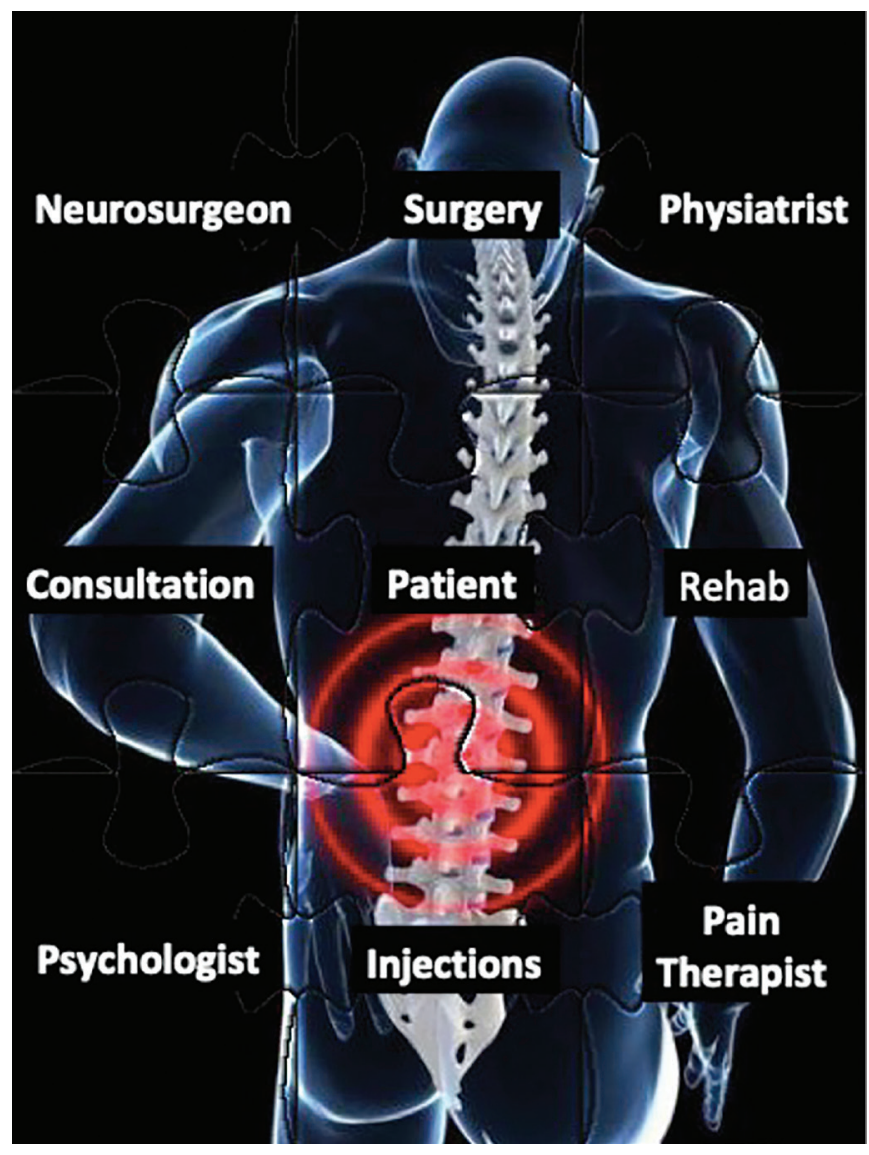

Fig. 3 - Puzzle showing the simultaneous multidisciplinary care pathway for low back pain patients.

that patients need. We create a program as a "personalized puzzle" (Fig. 3), in which patient is at the center of the picture surrounded by all treatments and consultations needed (other pieces of the puzzle to compose the picture). As in the puzzle, only considering all the pieces together you can visualize the image, so only acting altogether simultaneously you can obtain an adequate pain relief and good recovery for you patient.

\section{Disclosures}

Financial support: This research received no specific grant from any funding agency in the public, commercial, or not-for-profit sectors. Conflict of interest: MS, DS, VM, FC, GM, TL, RC and MI have nothing to disclose. MA received scientific consultations from Health \& RCB and Clover Orthopedics S.R.L.

\section{References}

1. Hartvigsen J, Hancock MJ, Kongsted A, et al; Lancet Low Back Pain Series Working Group. What low back pain is and why we need to pay attention. Lancet. 2018;391(10137):2356-2367. CrossRef PubMed

2. Koes BW, Backes D, Bindels PJE. Pharmacotherapy for chronic non-specific low back pain: current and future options. Expert Opin Pharmacother. 2018;19(6):537-545. CrossRef PubMed 
3. Deyo RA, Mirza SK, Turner JA, Martin BI. Overtreating chronic back pain: time to back off? J Am Board Fam Med. 2009;22(1): 62-68. CrossRef PubMed

4. Rasu RS, Vouthy K, Crowl AN, et al. Cost of pain medication to treat adult patients with nonmalignant chronic pain in the United States. J Manag Care Spec Pharm. 2014;20(9):921-928. PubMed

5. Gaskin DJ, Richard P. The economic costs of pain in the United States. J Pain. 2012;13(8):715-724. CrossRef PubMed

6. Mayer S, Spickschen J, Stein KV, Crevenna R, Dorner TE, Simon $J$. The societal costs of chronic pain and its determinants: the case of Austria. PLoS One. 2019;14(3):e0213889. CrossRef PubMed

7. Becker $\mathrm{A}$, Held $\mathrm{H}$, Redaelli $\mathrm{M}$, et al. Low back pain in primary care: costs of care and prediction of future health care utilization. Spine. 2010;35(18):1714-1720. CrossRef PubMed

8. Grimmer-Somers K, Prior M, Robertson J. Yellow flag scores in a compensable New Zealand cohort suffering acute low back pain. J Pain Res. 2008;1:15-25. CrossRef PubMed

9. Freidin MB, Lauc $G$, Allegri M, Primorac D, Williams FM. Using omics in chronic pain conditions to delineate mechanisms and provide new therapeutic strategies. Pain Manag. 2016;6(3): 211-215. CrossRef PubMed

10. Allegri M, Montella S, Salici F, et al. Mechanisms of low back pain: a guide for diagnosis and therapy. Version 2. F1000Res. 2016 Jun 28 [revised 2016 Jan1].

11. Trbojević-Akmačić I, Vučković F, Vilaj $\mathrm{M}$, et al. Plasma N-glycome composition associates with chronic low back pain. Biochim Biophys Acta, Gen Subj. 2018;1862(10):2124-2133. CrossRef PubMed

12. Dagostino C, Allegri M, Napolioni V, et al. CYP2D6 genotype can help to predict effectiveness and safety during opioid treatment for chronic low back pain: results from a retrospective study in an Italian cohort. Pharm Genomics Pers Med. 2018;11:179191. CrossRef PubMed

13. Cregg R, Russo G, Gubbay A, Branford R, Sato H. Pharmacogenetics of analgesic drugs. Br J Pain. 2013;7(4):189-208. CrossRef PubMed

14. Gatzinsky K, Eldabe S, Deneuville JP, et al. Optimizing the management and outcomes of failed back surgery syndrome: a proposal of a standardized multidisciplinary team care pathway. Pain Res Manag. 2019;2019:8184592. CrossRef PubMed

15. Murphy SE, Blake C, Power CK, Fullen BM. The effectiveness of a stratified group intervention using the STarTBack screening tool in patients with LBP-a non randomised controlled trial. BMC Musculoskelet Disord. 2013;14(1):342. CrossRef PubMed

16. Storm L, Rousing R, Andersen MO, Carreon LY. Usefulness of the STarT Back Screening Tool to predict pain problems after lumbar spine surgery. Dan Med J. 2018;65(12):A5517. PubMed

17. Karran EL, McAuley JH, Traeger AC, et al. Can screening instruments accurately determine poor outcome risk in adults with recent onset low back pain? A systematic review and meta-analysis. BMC Med. 2017;15(1):13. CrossRef PubMed

18. Qaseem A, Wilt TJ, McLean RM, Forciea MA; Clinical Guidelines Committee of the American College of Physicians. Noninvasive treatments for acute, subacute, and chronic low back pain: a clinical practice guideline from the American College of Physicians. Ann Intern Med. 2017;166(7):514-530. CrossRef PubMed

19. Malfliet A, Ickmans K, Huysmans $E$, et al. Best evidence rehabilitation for chronic pain part 3: low back pain. J Clin Med. 2019;8(7):E1063. CrossRef PubMed

20. Robinson JP, Leo R, Wallach J, McGough E, Schatman ME. Rehabilitative treatment for chronic pain. In: Stannard C, Kalso E, Ballantyne JC, eds. Evidence-based chronic pain management. Oxford, UK: Blackwell Publishing 2010: 407-423. CrossRef

21. van Middelkoop M, Rubinstein SM, Kuijpers T, et al. A systematic review on the effectiveness of physical and rehabilitation interventions for chronic non-specific low back pain. Eur Spine J. 2011;20(1):19-39. CrossRef PubMed

22. Willems P. Decision making in surgical treatment of chronic low back pain: the performance of prognostic tests to select patients for lumbar spinal fusion. Acta Orthop Suppl. 2013;84(349):1-35. CrossRef PubMed

23. Todd NV. The surgical treatment of non-specific low back pain. Bone Joint J. 2017;99-B(8):1003-1005. CrossRef PubMed

24. Stamm TA, Boesendorfer A, Omara M, Ritschl V, Štefanac S, Mosor E. Outcomes research in non-specific low back pain: knowledge transfer in clinical practice. Wien Klin Wochenschr. 2019;131(21-22):550-557. CrossRef PubMed

25. Musich S, Wang SS, Slindee LB, Keown K, Hawkins K, Yeh CS. Using pain medication intensity to stratify back pain among older adults. Pain Med. 2019;20(2):252-266. CrossRef PubMed

26. Juch JNS, Maas ET, Ostelo RWJG, et al. Effect of radiofrequency denervation on pain intensity among patients with chronic low back pain: the Mint Randomized Clinical Trials. JAMA. 2017;318(1):68-81. CrossRef PubMed

27. van Kleef $\mathrm{M}$, Vanelderen $\mathrm{P}$, Cohen SP, Lataster A, Van Zundert J, Mekhail N. Pain originating from the lumbar facet joints. Pain Pract. 2010;10(5):459-469. CrossRef PubMed

28. Gauci C. Radiofrequency neurotomy for chronic lumbar facet pain-interpreting the evidence. Pain Pract. 2010;10(3):261. CrossRef PubMed

29. van Kuijk SMJ, Van Zundert J, Hans G, et al. Flawed study design and incorrect presentation of data negatively impact potentially useful interventional treatments for patients with low back pain: a critical review of JAMA's MinT Study. Pain Pract. 2018;18(3):292-295. CrossRef PubMed

30. Nees TA, Riewe E, Waschke D, Schiltenwolf M, Neubauer E, Wang $\mathrm{H}$. Multidisciplinary pain management of chronic back pain: helpful treatments from the patients' perspective. J Clin Med. 2020;9(1):145. CrossRef PubMed 